\title{
Treatment of Perfluoroalkyl Acids by Heat-Activated Persulfate Under Conditions Representative of In Situ Chemical Oxidation
}

\author{
Thomas A. Bruton ${ }^{\mathrm{a}, 1}$ and David L. Sedlak ${ }^{\mathrm{a},{ }^{\star}}$ \\ aDept. of Civil and Environmental Engineering, University of California at Berkeley, Berkeley, CA \\ 94720 USA
}

\begin{abstract}
Perfluoroalkyl acids (PFAAs) are a class of organic contaminants notable for their extreme persistence. The unique chemical properties of these compounds make them difficult to remove from water using most standard water treatment techniques. To gain insight into the possibility of remediating contaminated groundwater by in situ chemical oxidation with heat-activated persulfate, PFAA removal and the generation of transformation products were evaluated under laboratory conditions. Solution $\mathrm{pH}$ had a strong influence on the removal of perfluorooctanoic acid (PFOA), resulting in its transformation into shorter-chain perfluorocarboxylic acids at $\mathrm{pH}$ values below 3 . The presence of chloride and aquifer sediments decreased the efficiency of the process by less than $25 \%$ under conditions likely to be encountered in drinking water aquifers.

Perfluorooctane sulfonate (PFOS) was not transformed by heat-activated persulfate under any of the conditions tested. Despite challenges related to the need to manipulate aquifer $\mathrm{pH}$, the possible generation of undesirable short-chain perfluorinated carboxylic acids (PFCAs) and chlorate, and metals mobilization, heat-activated persulfate may be a useful treatment technology for sites contaminated with perfluorinated carboxylic acids and fluorotelomer-based compounds, including those used in current-generation aqueous film-forming foams.
\end{abstract}

\section{Keywords}

PFOA; PFOS; PFAS; persulfate; in situ chemical oxidation; remediation

\section{INTRODUCTION}

\begin{abstract}
Perfluoroalkyl acids (PFAAs) are a family of organofluorine surfactants that contain a fully fluorinated carbon chain attached to an acid moiety. The high strength of the carbon-fluorine bonds enhances the stability of PFAAs, and the perfluoroalkyl chain and the polar acid group give them excellent surfactant properties. ${ }^{1-3}$ PFAAs comprise a subgroup of the polyand perfluoroalkyl substances (PFAS) - a large and diverse class of organofluorine compounds that share in common the perfluoroalkyl functional group. ${ }^{4}$ Due to their unique chemical properties, PFAAs have been used for decades in numerous industrial and manufacturing processes. ${ }^{5}$ Among the PFAAs, perfluoroalkyl carboxylic acids (PFCAs) and
\end{abstract}

\footnotetext{
*Corresponding author, sedlak@berkeley.edu, phone 1 (510) 643-0256.

${ }^{1}$ Present address: Green Science Policy Institute, Berkeley, CA, USA
} 
perfluoroalkane sulfonic acids (PFSAs) have been produced in the greatest quantities (e.g., approximately 3200-7300 tons of PFCAs were produced globally between 1951 and 20046). The eight-carbon acids, perfluorooctanoic acid (PFOA) and perfluorooctane sulfonic acid (PFOS), as well as polyfluorinated compounds containing a perfluorooctyl group, have been particularly important in commerce. ${ }^{6}$

Some of the same chemical properties that make PFAAs commercially useful are problematic when the compounds are released to the environment. PFSAs with six or more carbons and PFCAs with seven or more perfluorinated carbons are considered to be persistent, bioaccumulative, and toxic. ${ }^{7}$ Shorter-chain PFAAs are less bioaccumulative in animals, but appear to share certain of the persistent and toxic characteristics of their longchain homologues. Both PFCAs and PFSAs are strong acids that exist mainly in anionic forms at environmentally relevant $\mathrm{pH}$ values. Their negative charge contributes to their relatively high water solubilities, which makes them mobile in the aquatic environment. ${ }^{2,8,9}$ Recognition of their toxicity, stability, and long-range transport potential led to a phase out of long-chain PFAA production in North America and Europe starting in 2000.

Nevertheless, these compounds continue to be detected in water, soil and biota. In particular, the presence of PFAAs in drinking water supplies at concentrations ranging from approximately 1 to $1,000 \mathrm{ng} / \mathrm{L}$ has become a topic of concern. ${ }^{10,11}$ For example, in 2016 the U.S. EPA issued a Lifetime Health Advisory of $70 \mathrm{ng} / \mathrm{L}$ for PFOA, PFOS, or the sum of PFOA and PFOS. ${ }^{12}$ A number of U.S. states including New Jersey and Minnesota have issued their own lower science-based drinking water guidelines for PFOA, PFOS, and other PFAAs. ${ }^{13}$

PFAAs enter water supplies through various pathways, including emissions from manufacturing facilities, ${ }^{14,}{ }^{15}$ land application of biosolids, ${ }^{16}$ landfill leachate, ${ }^{17}$ and the use of aqueous film-forming foams (AFFF). ${ }^{2,18}$ Proximity to PFAA point sources has been linked to increased frequency of detection of PFAAs in drinking water, ${ }^{10}$ and the concentration of PFAAs in drinking water has been correlated with serum levels of PFAAs in humans. ${ }^{19}$ Results from epidemiological studies suggest associations between serum PFAA levels and adverse health outcomes, ${ }^{20}$ including kidney and testicular cancer.

As concerns about contamination increase, there is a growing need for technologies to remediate PFAA-contaminated groundwater. ${ }^{21}$ PFAAs are resistant to biodegradation and hydroxyl radical-based advanced oxidation processes ${ }^{22}$ but several researchers have reported that persulfate $\left(\mathrm{S}_{2} \mathrm{O}_{8}{ }^{2-}\right)$-based treatments degrade PFCAs. In this process, sulfate radical $\left(\mathrm{SO}_{4}{ }^{-}\right)$, produced by photolysis of $\mathrm{S}_{2} \mathrm{O}_{8}{ }^{2-}$ by ultraviolet light ${ }^{23,24}$ or thermolysis, 25-29 reacts with PFOA to form shorter-chain PFCAs. The proposed mechanism of PFOA decomposition involves sequential cleavage of $-\mathrm{CF}_{2}$ units, with formation of shorter-chain PFCAs and liberation of $\mathrm{F}^{-}$and $\mathrm{CO}_{2} \cdot{ }^{22,23,30} \mathrm{~A}$ simplified reaction can be used to represent the multi-step mechanism responsible for the transformation of PFOA to perfluoroheptanoic acid (PFHpA):

$$
\mathrm{CF}_{3}\left(\mathrm{CF}_{2}\right)_{6} \mathrm{COO}^{-}+\mathrm{SO}_{4}^{\bullet-}+2 \mathrm{H}_{2} \mathrm{O} \rightarrow \mathrm{CF}_{3}\left(\mathrm{CF}_{2}\right)_{5} \mathrm{COO}^{-}+\mathrm{SO}_{4}^{2-}+2 \mathrm{~F}^{-}+\mathrm{CO}_{2}+4 \mathrm{H}^{+}
$$


The subsequent steps (i.e., $\mathrm{PFHpA}$ oxidation by $\mathrm{SO}_{4}{ }^{--}$to produce perfluorohexanoic acid), follow an analogous mechanism.

Reports of PFOS degradation by persulfate are inconsistent. One research group employed $\mathrm{S}_{2} \mathrm{O}_{8}{ }^{2-}$ concentrations of up to $84 \mathrm{mM}$ and activation temperatures up to $60^{\circ} \mathrm{C}$, but observed no PFOS defluorination, ${ }^{27}$ whereas another research team reported up to $22.5 \%$ defluorination of PFOS using $18.5 \mathrm{mM}$ of heat-activated $\mathrm{S}_{2} \mathrm{O}_{8}{ }^{2-}$. 31

The majority of studies on $\mathrm{S}_{2} \mathrm{O}_{8}{ }^{2-}$ treatment of PFAAs have been performed without $\mathrm{pH}$ control, and in the absence of inorganic solutes, organic matter, and surfaces that are typically present in the aquatic environment. Reactions between $\mathrm{SO}_{4}{ }^{-}$and solutes could lower the concentration of $\mathrm{SO}_{4}{ }^{--}$, which would reduce the efficiency of PFAA removal. The few studies that considered the effects of matrix components indicated that the presence of $\mathrm{Cl}^{-24}$ and soil ${ }^{27}$ reduced the efficiency of PFOA transformation by $\mathrm{S}_{2} \mathrm{O}_{8}{ }^{2-}$ because added impurities scavenged of $\mathrm{SO}_{4}{ }^{-}$.

To determine the potential for using heat-activated persulfate to treat groundwater contaminated with PFAAs, batch experiments were performed under controlled conditions designed to represent those encountered during in situ chemical oxidation (ISCO) treatment. The effects of $\mathrm{pH}$, chloride concentration and aquifer solids were examined using PFOA and PFOS as representative PFAAs. The results of this research can be used to identify conditions under which heat-activated persulfate is likely to be an effective remedial strategy for PFAA-contaminated aquifers.

\section{MATERIALS AND METHODS}

\subsection{Materials}

A list of the full names and abbreviations for PFAAs measured in this study is provided in Table S1. Analytical standards and isotopically labeled PFAA reference standards were obtained from Wellington Laboratories. Reagent grade PFOS $\left(40 \%\right.$ in $\left.\mathrm{H}_{2} \mathrm{O}\right)$ and PFOA (96\% purity) were purchased from Sigma Aldrich. HPLC-grade water and LC-MS-grade methanol were obtained from Fisher Scientific. All other chemicals and solvents were of the highest possible purity and were purchased from Fisher Scientific or Sigma Aldrich. Solutions were prepared in ultrapure water (18 M $\Omega$ ) from a Millipore system.

Uncontaminated aquifer sediment was prepared and characterized as described elsewhere. ${ }^{32}$ Characterization data for the sediment are reported in Table S2.

\subsection{Persulfate Oxidation Experiments}

Batch oxidation experiments were performed in sealed $15-$ or $50-\mathrm{mL}$ polypropylene or polystyrene centrifuge tubes containing 10 or $40 \mathrm{~mL}$ of solution. Concentrated aqueous stocks of PFOA or PFOS were added to ultrapure water to obtain the desired nominal concentration. Most experiments were performed with an initial PFOA or PFOS concentration of $0.5 \mu \mathrm{M}$, which is within the range that these compounds are typically detected at contaminated sites. An initial PFOA concentration of $5 \mu \mathrm{M}$ was used in one experiment to facilitate measurement of fluoride generation. In some experiments, small 
aliquots of $1.0 \mathrm{M} \mathrm{NaCl}$ were added to achieve initial chloride concentrations ranging from 1 to $500 \mathrm{mM}$. Sediment slurry experiments were performed as described above, with the addition of $20 \mathrm{~g} / \mathrm{L}$ dried aquifer solids. An initial $\mathrm{S}_{2} \mathrm{O}_{8}{ }^{2-}$ concentration of $50 \mathrm{mM}$ was achieved by addition of aliquots of $500 \mathrm{mM} \mathrm{Na}_{2} \mathrm{~S}_{2} \mathrm{O}_{8}$.

For experiments at fixed $\mathrm{pH}$ values, solutions were buffered at $\mathrm{pH} 8,6$, and 3 with $50 \mathrm{mM}$ borate, phosphate or $\mathrm{H}_{2} \mathrm{SO}_{4}$, respectively. Under the conditions studied (e.g., $85^{\circ} \mathrm{C}$ ), persulfate decomposition occurs rapidly according to this overall reaction ${ }^{33}$ :

$$
\mathrm{S}_{2} \mathrm{O}_{8}^{2-}+\mathrm{H}_{2} \mathrm{O} \rightarrow 2 \mathrm{SO}_{4}^{2-}+2 \mathrm{H}^{+}+\frac{1}{2} \mathrm{O}_{2}
$$

For field applications of this remedial technology, lower temperatures are typically used (e.g., $40-60^{\circ} \mathrm{C}$ ). Under these conditions, the rate at which persulfate is activated decreases, but the dominant reactions (i.e., persulfate conversion to sulfate radical and subsequent reactions of persulfate with PFCAs and other solutes) remain the same. The acid produced in reaction 2 caused a decrease in $\mathrm{pH}$, requiring addition of aliquots of $1 \mathrm{~N} \mathrm{NaOH}$ at 30 -minute intervals to maintain near constant $\mathrm{pH}$ conditions during the experiments. The maximum temporary decrease in $\mathrm{pH}$ observed during a buffered experiment was 0.4 units. As an additional measure to limit the extent of $\mathrm{pH}$ change in the buffered experiments, smaller aliquots of persulfate were added (i.e., $10 \mathrm{mM}$ increments instead of $50 \mathrm{mM}$ ). In experiments without an added $\mathrm{pH}$ buffer, decomposition of $50 \mathrm{mM} \mathrm{S}_{2} \mathrm{O}_{8}{ }^{2-}$ decreased $\mathrm{pH}$ values to 1.3 when all of the $\mathrm{S}_{2} \mathrm{O}_{8}{ }^{2-}$ decomposed.

All experiments were performed in an $85^{\circ} \mathrm{C}$ water bath, as described in detail elsewhere. ${ }^{32}$ Briefly, reactors were placed in the hot-water bath after addition of the persulfate and were removed from the bath momentarily to withdraw samples at pre-determined time points. Most experiments used a $50 \mathrm{mM}$ initial concentration of $\mathrm{S}_{2} \mathrm{O}_{8}{ }^{2-}$ and were sampled for 7.5 hours. In a subset of experiments, additional persulfate aliquots were added after the first 7.5-hour period to simulate the effect of additional treatment.

Control experiments without persulfate were performed to assess PFAA losses unrelated to $\mathrm{S}_{2} \mathrm{O}_{8}{ }^{2-}$ treatment, including controls in which samples were acidified to $\mathrm{pH}$ values of 1 or 2 with $\mathrm{H}_{2} \mathrm{SO}_{4}$. Most experiments were carried out in duplicate or triplicate, and the results presented represent averages plus or minus one standard deviation. Experiments examining the effect of chloride used a single reactor for each initial $\mathrm{Cl}^{-}$concentration.

All samples were diluted in a combination of HPLC-grade water and methanol prior to analysis, as described in detail elsewhere. ${ }^{32}$ Samples from sediment slurry experiments were separated by centrifugation, and the sediments were subjected to additional solvent extraction to quantify the concentration of PFAAs sorbed to aquifer solids, as described previously. ${ }^{32}$ Samples for $\mathrm{F}^{-}$analysis were stored at $4^{\circ} \mathrm{C}$ prior to analysis, and were typically analyzed within two days. Samples for dissolved organic carbon (DOC) determination were filtered sequentially through $0.7 \mu \mathrm{m}$ and $0.2 \mu \mathrm{m}$ syringe filters, diluted five times in $500 \mathrm{mM}$ borate buffer, and stored at $4^{\circ} \mathrm{C}$ for less than eight hours prior to measurement. Samples were analyzed for persulfate and $\mathrm{pH}$ immediately after collection. 


\subsection{Analytical Methods}

PFAAs were quantified by LC-MS/MS operating in the negative electrospray ionization mode, using procedures and equipment described previously. ${ }^{32,34} \mathrm{~A}$ list of ion transitions monitored and MS parameters is provided in Table S3. Ultra-short-chain PFAAs, ${ }^{35}$ including two- and three-carbon PFCAs and PFSAs, were not included in the analytical method.

Established methods were used for determination of all other analytes. ${ }^{32}$ Persulfate was quantified by the KI colorimetric method. ${ }^{36}$ Fluoride, chloride, and chlorate were measured using a Dionex ICS-1100 ion chromatograph with a mobile phase of $0.8 \mathrm{mM} \mathrm{NaHCO}_{3}$ and $4.5 \mathrm{mM} \mathrm{Na}_{2} \mathrm{CO}_{3}$. Standard addition was used for quantification of fluoride. DOC was measured using a Shimadzu TOC-V CSH, and soil organic matter was quantified by loss-onignition. ${ }^{37}$

\section{RESULTS AND DISCUSSION}

\subsection{Unbuffered sediment free experiments}

In unbuffered water at $85^{\circ} \mathrm{C}, 99.5 \%$ of the added persulfate decomposed after $6 \mathrm{hr}$. Decomposition of $50 \mathrm{mM} \mathrm{S}_{2} \mathrm{O}_{8}{ }^{2-}$ followed pseudo-first order kinetics with a rate constant of $2.3 \times 10^{-4} \mathrm{~s}^{-1} \pm 0.02 \times 10^{-4} \mathrm{~s}^{-1}$, which agreed with results from previous studies ${ }^{38}$ (Figure S1).

In the absence of buffer, sulfate radicals generated through $\mathrm{S}_{2} \mathrm{O}_{8}{ }^{2-}$ decomposition reacted with PFOA, yielding $98 \%$ loss of PFOA and production of shorter-chain PFCAs as transformation products (Figure 1a). Data were consistent with the sequential - $\left(\mathrm{CF}_{2}\right)$ cleavage mechanism (reaction 1), with PFHpA reaching its maximum concentration first, followed by PFHxA, perfluoropentanoic acid (PFPeA), and perfluorobutyric acid (PFBA), as in other studies. ${ }^{24-27}$ At the end of the experiment, C4 to C7 PFCAs accounted for approximately $24 \%$ of the PFOA loss. A heated control containing PFOA without persulfate indicated that PFOA loss due to other processes (e.g., heating or sorption) was negligible. This conclusion was supported by the observed increase in $\mathrm{F}^{-}$(Figure 1b). A mass balance on fluorine was determined by summing the fluorine contained in measured PFCAs and $\mathrm{F}^{-}$ (Eqns. 3 and 4).

$$
\begin{aligned}
\mathrm{F}_{\mathrm{TOT}}=([\mathrm{PFOA}] * 15)+([\mathrm{PFHpA}] & * 13)+([\mathrm{PFHxA}] * 11) \\
& +([\mathrm{PFPeA}] * 9)+([\mathrm{PFBA}] * 7)+\left[\mathrm{F}^{-}\right] \\
& \mathrm{F}_{\text {Mass Balance }}=\frac{\mathrm{F}_{\mathbf{T O T}}}{\mathrm{F}_{\text {TOT }, \mathbf{0}}} \times 100 \%
\end{aligned}
$$

The $\mathrm{F}^{-}$mass balance ranged from $95-110 \%$ in experiments with an initial PFOA concentration of $5 \mu \mathrm{M}$. Fluoride was detected in experiments conducted with $0.5 \mu \mathrm{M}$ PFOA, 
but the mass balance was not reproducible due to the difficulty of accurately quantifying lower $\mathrm{F}^{-}$concentrations in a high-salt matrix.

\subsection{Effect of $\mathrm{pH}$}

Solution $\mathrm{pH}$ had a strong effect on the transformation of PFOA to shorter-chain PFCAs by heat-activated persulfate (Figure 2). In experiments buffered at $\mathrm{pH} 6$ and pH 8, no shorterchain PFCAs were detected. In experiments conducted at $\mathrm{pH} 8$, the small observed decrease in the concentration of PFOA may have been due to sorption losses to the reactor walls. At $\mathrm{pH} 3$, treatment with $10 \mathrm{mM} \mathrm{S}_{2} \mathrm{O}_{8}{ }^{2-}$ resulted in conversion of 7\% of PFOA to PFHpA. Treatment with $20 \mathrm{mM} \mathrm{S}_{2} \mathrm{O}_{8}{ }^{2-}$ at $\mathrm{pH} 3$ increased PFOA conversion to $20 \%$ and resulted in formation of PFHpA, PFHxA, PFPeA, and PFBA. PFOA transformation was greatest in reactors without $\mathrm{pH}$ control. In these reactors, $\mathrm{PFOA}$ conversion was $57 \%$ and the $\mathrm{pH}$ was approximately 2.0 after decomposition of the first $10 \mathrm{mM}$ aliquot of $\mathrm{S}_{2} \mathrm{O}_{8}{ }^{2-}$, and PFOA conversion was $100 \%$ and $\mathrm{pH}$ was approximately 1.8 after decomposition of $20 \mathrm{mM} \mathrm{S}_{2} \mathrm{O}_{8}{ }^{2-}$. The $\mathrm{pH}$ dropped to 1.3 after decomposition of $50 \mathrm{mM} \mathrm{S}_{2} \mathrm{O}_{8}{ }^{2-}$. Experiments conducted at initial pH values of 1.0 and 2.0 resulted in even higher rates of PFOA loss (Figure S2).

Previous reports of PFOA decomposition by heat-activated persulfate have indicated conflicting results with respect to the effect of $\mathrm{pH}$ on PFOA removal. Among these studies, two research groups did not control $\mathrm{pH},{ }^{25,27}$ two adjusted the initial $\mathrm{pH}$ but allowed it to decrease throughout the reactions, ${ }^{26,28}$ and one performed experiments at fixed $\mathrm{pH}$ values of $1,8.2$, and $13 .{ }^{29}$ Of the two groups that adjusted initial $\mathrm{pH}$ (but did not hold $\mathrm{pH}$ at a fixed value throughout the reaction) one reported that the extent of PFOA transformation increased with increasing initial $\mathrm{pH}$ (at initial $\mathrm{pH}$ values ranging from 2.5 to 9.2), ${ }^{26}$ while the other observed the opposite trend (at initial $\mathrm{pH}$ values ranging from 2.5 to 11 ). ${ }^{28}$ The study in which greater PFOA removal occurred at high $\mathrm{pH}^{26}$ employed $\mathrm{HCl}$ to acidify reactors that started out at $\mathrm{pH}$ values below 7.1. Under these conditions it is possible that scavenging of $\mathrm{SO}_{4}{ }^{-}$by $\mathrm{Cl}^{-}$, as discussed below, explains the observed trend. In the study in which fixed $\mathrm{pH}$ conditions were employed, loss of PFOA and production of shorter-chain PFCAs was observed at $\mathrm{pH} 1$, but not at $\mathrm{pH} 8.2$ or $13 .{ }^{29}$ The same study also indicated that PFOA transformation to shorter-chain PFCAs did not occur until sequential addition of $\mathrm{S}_{2} \mathrm{O}_{8}{ }^{2-}$ caused the $\mathrm{pH}$ to drop to approximately 3 .

Possible explanations for the observed relationship between PFOA removal and $\mathrm{pH}$ include: 1) a reduction in reaction efficiency as $\mathrm{SO}_{4}{ }^{--}$is converted into $\mathrm{HO}^{\bullet}$ by reaction with $\mathrm{OH}^{-} ; 2$ ) increased $\mathrm{S}_{2} \mathrm{O}_{8}{ }^{2-}$ decomposition kinetics at low $\mathrm{pH} ; 3$ ) an increase in reaction efficiency due to increasing concentrations of protonated PFOA or a related intermediate at low $\mathrm{pH}$; and, 4) an increase in reaction efficiency due to protonation of $\mathrm{SO}_{4}{ }^{-}$.

At high $\mathrm{pH}$ values, $\mathrm{SO}_{4}{ }^{--}$reacts with $\mathrm{OH}^{-}$to form $\mathrm{HO}^{\bullet}(\text { Eqn. } 5)^{39}$

$$
\mathrm{SO}_{4}^{\bullet-}+\mathrm{OH}^{-} \rightarrow \mathrm{HO}^{\bullet}+\mathrm{SO}_{4}^{2-} \quad k_{5}=8.3 \times 10^{7} \mathrm{M}^{-1} \mathrm{~s}^{-1}
$$

Under sufficiently alkaline conditions, the conversion from $\mathrm{SO}_{4}{ }^{\cdot-}$ to $\mathrm{HO}$ is nearly instantaneous. ${ }^{34} \mathrm{HO}$ does not react at an appreciable rate with $\mathrm{PFOA},{ }^{40}$ so conversion of 
$\mathrm{SO}_{4}{ }^{--}$to $\mathrm{HO}^{\bullet}$ at higher $\mathrm{pH}$ could explain the lack of PFOA loss observed at increased $\mathrm{pH}$. The relative importance of the reaction in Eqn. 5 can be approximated by accounting for all of the known sinks for $\mathrm{SO}_{4}^{--}{ }^{-41}$

$$
\mathrm{f}_{\mathrm{PFOA}}=\frac{\mathrm{k}_{\mathrm{PFOA}}[\mathrm{PFOA}]}{\mathrm{k}_{5}\left[\mathrm{OH}^{-}\right]+\mathrm{k}_{6}\left[\mathrm{H}_{2} \mathrm{O}\right]+\mathrm{k}_{7}\left[\mathrm{~S}_{2} \mathrm{O}_{8}^{2-}\right]+\mathrm{k}_{8}[\mathrm{PFOA}]} \quad(6)^{24}
$$

where $\mathrm{f}_{\mathrm{PFOA}}$ is the fraction of $\mathrm{SO}_{4}{ }^{\cdot-}$ reacting with PFOA, $\mathrm{k}_{\mathrm{PFOA}}$ is the second order rate constant for the reaction of $\mathrm{SO}_{4}{ }^{--}$and PFOA, and $\mathrm{k}_{5}, \mathrm{k}_{6}$, and $\mathrm{k}_{7}$ are the second order reaction rate constants for the reactions in Eqns. 5 - 7, respectively.

$$
\begin{array}{cc}
\mathrm{SO}_{4}^{\bullet-}+\mathrm{H}_{2} \mathrm{O} \rightarrow \mathrm{HO}^{\bullet}+\mathrm{HSO}_{4}^{-} & k_{6}=1.8 \times 10^{-3} \mathrm{M}^{-1} \mathrm{~s}^{-1} \quad(7)^{24} \\
\mathrm{SO}_{4}^{\bullet-}+\mathrm{S}_{2} \mathrm{O}_{8}^{2-} \rightarrow \mathrm{S}_{2} \mathrm{O}_{8}^{\bullet-}+\mathrm{SO}_{4}^{2-} & k_{7}=1.8 \times 10^{5} \mathrm{M}^{-1} \mathrm{~s}^{-1} \quad(8)^{24} \\
\mathrm{SO}_{4}^{\bullet-}+\mathrm{PFOA} \rightarrow \text { PFHpA }+ \text { products } & k_{8}=2.6 \times 10^{5} \mathrm{M}^{-1} \mathrm{~s}^{-1}
\end{array}
$$

Calculation of $\mathrm{f}_{\mathrm{PFOA}}$ as a function of $\mathrm{pH}$ indicates that the estimated fraction of $\mathrm{SO}_{4}{ }^{--}$ reacting with PFOA remains constant at low-to-circumneutral $\mathrm{pH}$ and only begins to decrease when $\mathrm{pH}$ increases above 8 (Figure $\mathrm{S} 3$ ). On the basis of this analysis, conversion of $\mathrm{SO}_{4}{ }^{--}$to $\mathrm{HO}^{\bullet}$ does not explain the observed $\mathrm{pH}$ dependence.

Another potential explanation for the $\mathrm{pH}$ dependence of PFOA transformation is that the decomposition rate of $\mathrm{S}_{2} \mathrm{O}_{8}{ }^{2-}$ increases as $\mathrm{pH}$ decreases. The kinetics of $\mathrm{S}_{2} \mathrm{O}_{8}{ }^{2-}$ thermolysis in deionized water conform to the following rate law:

$$
-\frac{\mathrm{d}\left[\mathrm{S}_{2} \mathrm{O}_{8}^{2-}\right]}{\mathrm{dt}}=\mathrm{k}_{\mathrm{N}}\left[\mathrm{S}_{2} \mathrm{O}_{8}^{2-}\right]+\mathrm{k}_{\mathrm{A}}\left[\mathrm{H}^{+}\right]\left[\mathrm{S}_{2} \mathrm{O}_{8}^{2-}\right]+\mathrm{k}_{\mathrm{B}}\left[\mathrm{OH}^{-}\right]\left[\mathrm{S}_{2} \mathrm{O}_{8}^{2-}\right]
$$

where $k_{N}, k_{A}$, and $k_{B}$ are equal to $0.81 \mathrm{~h}^{-1}, 13 \mathrm{~h}^{-1}$, and $0.27 \mathrm{~h}^{-1}$, at $\mathrm{T}=85^{\circ} \mathrm{C}$, respectively. 38

The rate of persulfate decay exhibits little $\mathrm{pH}$-dependence between $\mathrm{pH} 2$ and 8 . Below $\mathrm{pH} 2$, the contribution of acid catalysis becomes noticeable. ${ }^{29}$ The $2 \%$ increase of overall $\mathrm{S}_{2} \mathrm{O}_{8}{ }^{2-}$ decomposition rate that is predicted as $\mathrm{pH}$ decreases from 8 to 3 is unlikely to account for the significant variation in PFOA transformation observed. 
Another potential explanation for the increased PFOA loss observed at low $\mathrm{pH}$ values is that a protonated species that has a $\mathrm{pK}_{\mathrm{a}}$ value below 3 is involved in the transformation reaction. For instance, protonated PFOA may react more readily with $\mathrm{SO}_{4}{ }^{\cdot-}$ than its anionic form because of reduced electrostatic repulsion. The $\mathrm{pK}_{\mathrm{a}}$ of PFOA is uncertain, with estimates ranging from $-0.5^{42}$ to $3.8 .^{43}$ If the protonated form is the only species reacting at a significant rate, the observed rate of reaction between $\mathrm{SO}_{4}{ }^{-}$and PFOA would increase by a factor of 10 for every unit decrease in $\mathrm{pH}$ as the $\mathrm{pH}$ approaches the $\mathrm{pK}_{\mathrm{a}}$. Evidence for the protonation of PFOA at low $\mathrm{pH}$ was observed in persulfate-free control reactors conducted at different $\mathrm{pH}$ values. PFOA loss in controls increased as initial $\mathrm{pH}$ decreased from 3 to 1 , presumably due to volatilization of protonated PFOA at the elevated temperatures employed. 29

A related explanation is that $\mathrm{SO}_{4}{ }^{--}$was protonated at low $\mathrm{pH}$, or that an acid-catalyzed reaction was involved in the transformation of PFOA. The $\mathrm{pK}_{\mathrm{a}}$ of $\mathrm{SO}_{4}{ }^{--}$has not been reported, ${ }^{39}$ but it is expected to be less than $2 .{ }^{44}$ It has been hypothesized that the neutral $\mathrm{H}$ ${ }^{+} \mathrm{SO}_{4}{ }^{\cdot-}$ ion pair could have a higher rate constant with anions than the $\mathrm{SO}_{4}{ }^{--}$anion alone. ${ }^{45}$ The uncertainty of the $\mathrm{pK}_{\mathrm{a}}$ values for $\mathrm{PFOA}$ and $\mathrm{SO}_{4}{ }^{-}$make it difficult to differentiate between these two possible explanations. Additional research is needed to determine which of the three most likely explanations (i.e., protonation of PFOA, acid catalysis or protonation of $\mathrm{SO}_{4}{ }^{-}$) explain the observed effect of $\mathrm{pH}$ on PFOA transformation.

A parallel set of experiments was conducted using PFOS instead of PFOA. No loss of PFOS was observed in experiments conducted with initial $\mathrm{S}_{2} \mathrm{O}_{8}{ }^{2-}$ concentrations as high as $50 \mathrm{mM}$ (Figure S4). This observation agrees with data reported in a recent study ${ }^{27}$ but is at odds with the results of a study in which PFOS was transformed by heat-activated persulfate to produce shorter-chain PFCAs. ${ }^{31}$ It is difficult to reconcile the results of the study in which PFOS degradation was reported for several reasons. First, the temperature at which persulfate activation was performed was not reported. Second, the researchers also reported loss of $1.45 \%$ of the PFOS by defluorination after 12 hours of treatment with $\mathrm{S}_{2} \mathrm{O}_{8}{ }^{2-}$ at room temperature - an unexpected finding given the slow rate of persulfate thermolysis under these conditions. Finally, the measurements of PFOS and other PFAAs were made without internal standards, which makes it difficult to determine if instrument sensitivity was affected by changes in the matrix that occurred as the persulfate decomposed.

\subsection{Effect of Chloride}

The presence of chloride slowed the transformation of PFOA by heat-activated persulfate under acidic conditions (Figure 3). In experiments with $50 \mathrm{mM} \mathrm{S}_{2} \mathrm{O}_{8}{ }^{2-}$ and varying initial concentrations of $\mathrm{Cl}^{-}$from concentrations typical of freshwater (i.e., $1 \mathrm{mM}$ ) up to conditions encountered in saline groundwater (i.e., $700 \mathrm{mM}$ ), persulfate disappeared at the same rate as observed in chloride-free experiments. Furthermore, the $\mathrm{pH}$ change observed in these experiments was comparable to that observed in the chloride-free system, with final $\mathrm{pH}$ values ranging from 1.4 to 1.7 .

$\mathrm{At}^{-}$concentrations ranging from 1 to $3 \mathrm{mM}$, PFOA was completely removed. Detectable transformation products (i.e., shorter-chain PFCAs) accounted for 13 to $19 \%$ of initial PFOA, indicating a similar degree of mineralization to results obtained under $\mathrm{Cl}^{-}$-free 
conditions. PFOA removal decreased at initial $\mathrm{Cl}^{-}$concentrations above $10 \mathrm{mM}$, with PFOA transformation accounting for just $6 \%$ and $3 \%$ of initial PFOA at initial $\mathrm{Cl}^{-}$concentrations of 100 and $500 \mathrm{mM}$, respectively. Pseudo-first order decay constants for PFOA were calculated from data collected during the first hour of the experiment. A plot of initial $\mathrm{Cl}^{-}$ concentration versus the observed rate constants for PFOA loss demonstrates an inverse relationship between the amount of chloride present in solution and PFOA removal rates (Figure S5). These results indicate that the presence of $\mathrm{Cl}^{-}$decreases the efficiency of PFOA treatment, likely due to scavenging of sulfate radicals by $\mathrm{Cl}^{-}$. The relationship observed between initial $\mathrm{Cl}^{-}$concentration and extent of PFOA removal is consistent with an analysis of the relevant reactions. $\mathrm{SO}_{4}{ }^{--}$reacts with $\mathrm{Cl}^{-}$at rates that are approximately three orders of magnitude higher than with PFOA:

$$
\mathrm{SO}_{4}^{\bullet-}+\mathrm{Cl}^{-} \rightarrow \mathrm{Cl}^{\bullet}+\mathrm{SO}_{4}^{2-} \quad k_{11}=4.7 \times 10^{8} \mathrm{M}^{-1} \mathrm{~s}^{-1} \quad(11)^{24}
$$

The fate of $\mathrm{Cl}^{\bullet}$ is $\mathrm{pH}$-dependent. ${ }^{46} \mathrm{At} \mathrm{pH} \geq 5, \mathrm{Cl}^{\bullet}$ is converted to $\mathrm{HO}^{\bullet}$ with regeneration of $\mathrm{Cl}^{-}$. At $\mathrm{pH}<5, \mathrm{Cl}^{-}$is oxidized to $\mathrm{ClO}_{3}{ }^{-}$through sequential reactions with $\mathrm{Cl}^{-}$. During this process, some of the $\mathrm{Cl}^{\circ}$ or other intermediates may react with other contaminants if they are present at high concentrations. Under the acidic $\mathrm{pH}$ conditions that occur in the absence of buffer, chloride outcompeted PFOA for $\mathrm{SO}_{4}{ }^{-}$and PFOA could not be transformed until all of the chloride had been converted to $\mathrm{ClO}_{3}{ }^{-}$. This finding is consistent with a study in which PFOA transformation occurred only after complete conversion of $\mathrm{Cl}^{-}$to $\mathrm{ClO}_{3}{ }^{-}$when $\mathrm{SO}_{4}{ }^{-}$ was produced by photolysis of persulfate. ${ }^{24}$ Under typical conditions encountered in groundwater ${ }^{47}$ (i.e., $1 \mathrm{mM} \mathrm{Cl}^{-}$), scavenging of $\mathrm{SO}_{4}{ }^{--}$by $\mathrm{Cl}^{-}$is expected to have a negligible effect on the efficiency of treatment due to the high concentration of $\mathrm{S}_{2} \mathrm{O}_{8}{ }^{2-}$ used for in situ chemical oxidation. However, in brackish groundwater or groundwater contaminated with chloride, $\mathrm{S}_{2} \mathrm{O}_{8}{ }^{2-}$ consumption by chloride could increase the cost of PFCA remediation. In either case, precautions should be taken to monitor $\mathrm{ClO}_{3}{ }^{-}$concentrations, because $\mathrm{ClO}_{3}{ }^{-}$is associated with toxicity to the thyroid and other organs. Heath-activated persulfate treatment of typical groundwater containing a $1 \mathrm{mM}$ concentration of $\mathrm{Cl}-$ could generate $\mathrm{ClO}_{3}{ }^{-}$ concentrations well in excess of the World Health Organization's $700 \mu \mathrm{g} / \mathrm{L}$ provisional guideline. ${ }^{48}$

\subsection{Effect of Aquifer Sediments}

Persulfate decomposition in the presence of aquifer sediments was approximately $17 \%$ slower than the rate observed in the sediment free systems (Figure S1). The slight decrease in $\mathrm{S}_{2} \mathrm{O}_{8}{ }^{2-}$ decomposition rate may have been attributable to the higher starting $\mathrm{pH}$ in the slurry experiments caused by buffering by the sediments. Similar to the experiments in unbuffered water, $99.5 \%$ of the added persulfate was decomposed after 6 hours in the presence of sediments. Acid production from decomposition of the first aliquot of persulfate caused the $\mathrm{pH}$ to drop from 5.4 to 1.4 during the first 7.5 hours of the experiment. The second $50 \mathrm{mM}$ aliquot of persulfate did not result in further $\mathrm{pH}$ decrease.

The presence of aquifer sediments decreased the efficiency of heat-activated $\mathrm{S}_{2} \mathrm{O}_{8}{ }^{2-}$ treatment of PFOA (Figure 4a-c). In reactors containing aquifer sediments, treatment with 
$50 \mathrm{mM} \mathrm{S}_{2} \mathrm{O}_{8}{ }^{2-}$ resulted in loss of $86 \%$ of the PFOA, approximately $60 \%$ of which could be accounted for by C4-C7 homologues. Treatment with a second $50 \mathrm{mM}$ aliquot of $\mathrm{S}_{2} \mathrm{O}_{8}{ }^{2-}$ increased overall PFOA loss to $98 \%$. At the end of the experiment, $34 \%$ of total PFOA loss was accounted for by shorter-chain PFCAs, indicating partial mineralization of PFOA. Methanol extraction of the sediments resulted in recovery of only 3 to $10 \%$ of the total PFCAs, so sorption to sediments was not a major mechanism of PFOA loss under these conditions. Because the rate of $\mathrm{S}_{2} \mathrm{O}_{8}{ }^{2-}$ loss and change in $\mathrm{pH}$ during the experiment were similar to those observed in the absence of sediments, the decrease in PFCA treatment efficiency observed in the slurry reactors was likely due to scavenging of $\mathrm{SO}_{4}{ }^{-}$by inorganic anions (e.g., $\mathrm{Cl}^{-}$, metals), organic matter, or surfaces. This explanation is supported by measurements of $\mathrm{Cl}^{-}$and TOC concentrations, with concentrations decreasing rapidly at the beginning of the experiment (Figures S6 and S7). $\mathrm{Cl}^{-}$was converted into $\mathrm{ClO}_{3}{ }^{-}$within two hours (Figure S6). Another slurry experiment conducted in surficial soil with a higher organic matter content $(0.96 \%)$ than the aquifer sediment resulted in an even greater loss of PFOA treatment efficiency (Figure S8).

\subsection{Opportunities and Limitations for in situ Remediation Treatment of PFAAs}

In situ chemical oxidation by thermal activation of persulfate could prove useful at sites where PFCAs are the only type of PFAS present. It could also be useful at sites where fluorotelomer-based AFFF was used because PFASs in these formulations are readily converted into PFCAs by hydroxyl radical ${ }^{18}$ or sulfate radical. ${ }^{29}$ When PFCAs and PFSAs are present as co-contaminants, heat-activated persulfate could be employed in a treatmenttrain approach to reduce the contaminant mass in source zones as a complement to pumpand-treat remediation.

Heat-activated persulfate treatment could also be useful for mobilizing sorbed cationic and zwitterionic polyfluorinated compounds. Positively charged PFAS species were major components of several AFFF formulations. ${ }^{18}$ These cationic and zwitterionic species are suspected to comprise an important portion of total PFAS in contaminant source zones at AFFF-impacted sites because of their affinity for surfaces. ${ }^{49}$ If ISCO treatment results in oxidation of sorbed PFAS species, PFAAs would be released into the dissolved phase. Alternatively, persulfate ISCO could mobilize sorbed PFAA-precursors through cation exchange. Low-pH persulfate treatment will increase the concentration of $\mathrm{H}^{+}$and polyvalent cations, such as $\mathrm{Ca}^{2+}$, in groundwater, both of which could displace cationic or zwitterionic polyfluorinated compounds from sorption sites. After entering the dissolved phase, these PFAS would react with oxidants or could be removed by pump-and-treat systems. Few studies to date have investigated the affect of ISCO treatment on subsurface mobility of PFASs. One research group observed decreased PFAA transport in column studies with persulfate treatment at room temperature, ${ }^{50}$ but further research is needed to assess the impact of persulfate treatment on transport of polyfluorinated compounds under heatactivation conditions.

Site geochemistry is an important factor affecting the efficacy of heat-activated persulfate for in situ treatment for PFAAs and other PFAS. For instance, scavenging of $\mathrm{SO}_{4}{ }^{--}$by chloride or organic matter will reduce the efficacy of the treatment. Also, the high buffering capacity 
of carbonate-rich aquifers will make it difficult to lower groundwater $\mathrm{pH}$ to values necessary for successful treatment. Conversely, returning the $\mathrm{pH}$ of groundwater to circumneutral after $\mathrm{pH}$ persulfate treatment at low $\mathrm{pH}$ will be more difficult in poorly buffered aquifers. In such cases, permeable reactive barriers containing material capable of neutralizing acidity (e.g., $\mathrm{CaCO}_{3(\mathrm{~s})}$ ) could be installed downstream of the ISCO treatment zone to neutralize acidity. Irrespective of the means of neutralization, most cationic metals mobilized under acidic conditions should precipitate or adsorb after acidity is neutralized.

Another limitation of this technology is the potential for production of hazardous byproducts. Unless persulfate treatment results in complete mineralization of PFAAs, the treatment process will generate short-chain PFCAs. This is undesirable because these compounds are generally more mobile in the subsurface ${ }^{51}$ and less easily removed by sorptive technologies ${ }^{52}$ than long-chain PFCAs. Another potentially hazardous byproduct of oxidative PFAA treatment is HF. HF is a weak acid $\left(\mathrm{pK}_{\mathrm{a}}\right.$ of 3.2). If heat-activated persulfate is employed to treat PFCAs at low $\mathrm{pH}$, a substantial portion of the $\mathrm{F}^{-}$generated will be present in the protonated form. This is unlikely to pose substantial risks if AFFF in the source zone has been diluted, but the potential for exposure of workers to HF should be considered prior to initiating heat-activated persulfate treatment of PFAAs, especially if the source zone contains very high concentrations of PFASs. As mentioned previously, heatactivated persulfate also may generate concentrations of $\mathrm{ClO}_{3}{ }^{-}$at concentrations that could pose health risks to consumers of groundwater.

\section{CONCLUSIONS}

Under acidic conditions ( $\mathrm{pH} \leq 3$ ), heat-activated persulfate treatment resulted in transformation of PFOA into shorter-chain PFCAs, some of which were eventually mineralized. The presence of both $\mathrm{Cl}^{-}$and aquifer solids decreased the efficiency of PFOA treatment. Persulfate did not transform PFOS. Despite these limitations, the lack of other proven treatment options suggests that further investigation of heat-activated persulfate as an in situ treatment for PFCAs is warranted.

\section{Supplementary Material}

Refer to Web version on PubMed Central for supplementary material.

\section{ACKNOWLEDGEMENTS}

This study was supported by the U.S. National Institute for Environmental Health Sciences (NIEHS) Superfund Research Program (Grant P42 ES004705) and the Superfund Research Center at University of California, Berkeley. Additional support came from the Strategic Environmental Research and Development Program (SERDP ER2128). We thank our colleagues Erika Houtz, Shan Yi, and Katie Harding for insightful discussions and help in the laboratory. We also thank Dr. Christopher Higgins for helpful comments during the preparation of this manuscript.

\section{References}

1. Kissa E, Fluorinated surfactants: synthesis, properties, applications. M. Dekker New York: 1994.

2. Moody CA; Field JA, Perfluorinated Surfactants and the Environmental Implications of Their Use in Fire-Fighting Foams. Environmental Science \& Technology 2000, 34 (18), 3864-3870. 
3. Key BD; Howell RD; Criddle CS, Fluorinated organics in the biosphere. Environmental Science \& Technology 1997, 31 (9), 2445-2454.

4. Buck RC; Franklin J; Berger U; Conder JM; Cousins IT; de Voogt P; Jensen AA; Kannan K; Mabury SA; van Leeuwen SP, Perfluoroalkyl and polyfluoroalkyl substances in the environment: terminology, classification, and origins. Integrated environmental assessment and management 2011, 7 (4), 513-541. [PubMed: 21793199]

5. Kissa E, Fluorinated surfactants and repellents. CRC Press: 2001.

6. Prevedouros K; Cousins IT; Buck RC; Korzeniowski SH, Sources, fate and transport of perfluorocarboxylates. Environmental Science \& Technology 2006, 40 (1), 32-44. [PubMed: 16433330]

7. Scheringer M; Trier X; Cousins IT; de Voogt P; Fletcher T; Wang Z; Webster TF, Helsingør Statement on poly-and perfluorinated alkyl substances (PFASs). Chemosphere 2014, 114, 337-339. [PubMed: 24938172]

8. Shinoda K; Hato M; Hayashi T, Physicochemical properties of aqueous solutions of fluorinated surfactants. The Journal of Physical Chemistry 1972, 76 (6), 909-914.

9. Giesy JP; Kannan K, Peer reviewed: perfluorochemical surfactants in the environment. Environmental science \& technology 2002, 36 (7), 146A-152A. [PubMed: 11827047]

10. Hu XC; Andrews DQ; Lindstrom AB; Bruton TA; Schaider LA; Grandjean P; Lohmann R; Carignan CC; Blum A; Balan SA, Detection of Poly- and Perfluoroalkyl Substances (PFASs) in US Drinking Water Linked to Industrial Sites, Military Fire Training Areas, and Wastewater Treatment Plants. Environmental Science \& Technology Letters 2016, 3(10) 344-350. [PubMed: 27752509]

11. Xiao F; Simcik MF; Halbach TR; Gulliver JS, Perfluorooctane sulfonate (PFOS) and perfluorooctanoate (PFOA) in soils and groundwater of a US metropolitan area: Migration and implications for human exposure. Water Research 2015, 72, 64-74. [PubMed: 25455741]

12. U.S. Environmental Protection Agency. Drinking Water Health Advisories for PFOA and PFOS. $2016 \mathrm{https}: / / w w w . e p a . g o v / g r o u n d-w a t e r-a n d-d r i n k i n g-w a t e r / d r i n k i n g-w a t e r-h e a l t h-a d v i s o r i e s-$ pfoa-and-pfos . Accessed 19 Apr 2017.

13. Post GB; Gleason JA.; Cooper KR, Key scientific issues in developing drinking water guidelines for perfluoroalkyl acids: Contaminants of emerging concern. PLoS Biol 2017, 15 (12), e2002855. [PubMed: 29261653]

14. Davis KL; Aucoin MD; Larsen BS; Kaiser MA; Hartten AS, Transport of ammonium perfluorooctanoate in environmental media near a fluoropolymer manufacturing facility. Chemosphere 2007, 67 (10), 2011-2019. [PubMed: 17250873]

15. Hansen K-J; Johnson H; Eldridge J; Butenhoff J; Dick L, Quantitative characterization of trace levels of PFOS and PFOA in the Tennessee River. Environmental Science \& Technology 2002, 36 (8), 1681-1685. [PubMed: 11993863]

16. Lindstrom AB; Strynar MJ; Delinsky AD; Nakayama SF; McMillan L; Libelo EL; Neill M; Thomas L, Application of WWTP biosolids and resulting perfluorinated compound contamination of surface and well water in Decatur, Alabama, USA. Environmental science \& technology 2011, 45 (19), 8015-8021. [PubMed: 21513287]

17. Huset CA; Barlaz MA; Barofsky DF; Field JA, Quantitative determination of fluorochemicals in municipal landfill leachates. Chemosphere 2011, 82 (10), 1380-1386. [PubMed: 21194725]

18. Houtz EF; Higgins CP; Field JA; Sedlak DL, Persistence of perfluoroalkyl acid precursors in AFFF-impacted groundwater and soil. Environmental science \& technology 2013, 47 (15), 81878195. [PubMed: 23886337]

19. Hurley S; Houtz EF; Goldberg D; Wang M; Park J; Nelson DO; Reynolds P; Bernstein L; AntonCulver H; Horn-Ross P, Preliminary Associations between the Detection of Perfluoroalkyl Acids (PFAAs) in Drinking Water and Serum Concentrations in a Sample of California Women. Environmental Science \& Technology Letters 2016.

20. C8 Science Panel: C8 Probable Link Reports. http://www.c8sciencepanel.org/prob_link.html (accessed Oct. 3). 
21. Kucharzyk KH; Darlington R; Benotti M; Deeb R; Hawley E, Novel treatment technologies for PFAS compounds: A critical review. Journal of Environmental Management 2017, 204, 757-764. [PubMed: 28818342]

22. Vecitis C; Park H; Cheng J; Mader B; Hoffmann M, Treatment technologies for aqueous perfluorooctanesulfonate (PFOS) and perfluorooctanoate (PFOA). Frontiers of Environmental Science \& Engineering in China 2009, 3 (2), 129-151.

23. Hori H; Yamamoto A; Hayakawa E; Taniyasu S; Yamashita N; Kutsuna S; Kiatagawa H; Arakawa R, Efficient Decomposition of Environmentally Persistent Perfluorocarboxylic Acids by Use of Persulfate as a Photochemical Oxidant. Environmental Science \& Technology 2005, 39 (7), 2383 2388. [PubMed: 15871280]

24. Qian Y; Guo X; Zhang Y; Peng Y; Sun P; Huang C-H; Niu J; Zhou X; Crittenden JC, Perfluorooctanoic Acid Degradation Using UV-Persulfate Process: Modeling of the Degradation and Chlorate Formation. Environmental science \& technology 2015, 50 (2), 772-781. [PubMed: 26686982]

25. Hori H; Nagaoka Y; Murayama M; Kutsuna S, Efficient decomposition of perfluorocarboxylic acids and alternative fluorochemical surfactants in hot water. Environmental Science \& Technology 2008, 42 (19), 7438-7443. [PubMed: 18939583]

26. Liu CS; Higgins CP; Wang F; Shih K, Effect of temperature on oxidative transformation of perfluorooctanoic acid (PFOA) by persulfate activation in water. Separation and Purification Technology 2012, 91, 46-51.

27. Park S; Lee LS; Medina VF; Zull A; Waisner S, Heat-activated persulfate oxidation of PFOA, 6: 2 fluorotelomer sulfonate, and PFOS under conditions suitable for in-situ groundwater remediation. Chemosphere 2016, 145, 376-383. [PubMed: 26692515]

28. Lee Y-C; Lo S-L; Kuo J; Lin Y-L, Persulfate oxidation of perfluorooctanoic acid under the temperatures of 20-40 C. Chemical engineering journal 2012, 198, 27-32.

29. Sun B; Ma J; Sedlak DL, Chemisorption of Perfluorooctanoic Acid on Powdered Activated Carbon Initiated by Persulfate in Aqueous Solution. Environmental Science \& Technology 2016, 50 (14), 7618-7624. [PubMed: 27336204]

30. Hori H; Hayakawa E; Einaga H; Kutsuna S; Koike K; Ibusuki T; Kiatagawa H; Arakawa R, Decomposition of environmentally persistent perfluorooctanoic acid in water by photochemical approaches. Environmental science \& technology 2004, 38 (22), 6118-6124. [PubMed: 15573615]

31. Yang S; Cheng J; Sun J; Hu Y; Liang X, Defluorination of aqueous perfluorooctanesulfonate by activated persulfate oxidation. PloS one 2013, 8 (10), e74877. [PubMed: 24116016]

32. Bruton TA; Sedlak DL, Treatment of aqueous film-forming foam by heat-activated persulfate under conditions representative of in situ chemical oxidation. Environmental Science \& Technology 2017, 51 (23), 13878-13885. [PubMed: 29164864]

33. Liu H; Bruton TA; Doyle FM; Sedlak DL, In Situ Chemical Oxidation of Contaminated Groundwater by Persulfate: Decomposition by Fe(III)- and Mn(IV)-Containing Oxides and Aquifer Materials. Environmental Science \& Technology 2014, 48 (17), 10330-10336. [PubMed: 25133603]

34. Houtz EF; Sedlak DL, Oxidative conversion as a means of detecting precursors to perfluoroalkyl acids in urban runoff. Environmental science \& technology 2012, 46 (17), 9342-9349. [PubMed: 22900587]

35. Barzen-Hanson KA; Field JA, Discovery and Implications of C2 and C3 Perfluoroalkyl Sulfonates in Aqueous Film-Forming Foams and Groundwater. Environmental Science \& Technology Letters 2015, 2 (4), 95-99.

36. Liang CJ; Huang CF; Mohanty N; Kurakalva RM, A rapid spectrophotometric determination of persulfate anion in ISCO. Chemosphere 2008, 73 (9), 1540-1543. [PubMed: 18922560]

37. Schulte E; Kaufmann C; Peter J, The influence of sample size and heating time on soil weight loss-on-ignition. Communications in Soil Science \& Plant Analysis 1991, 22 (1-2), 159-168.

38. Johnson RL; Tratnyek PG; Johnson RO, Persulfate Persistence under Thermal Activation Conditions. Environmental Science \& Technology 2008, 42 (24), 9350-9356. [PubMed: 19174915] 
39. Neta P; Huie RE; Ross AB, Rate constants for reactions of inorganic radicals in aqueous solution. American Chemical Society: 1988.

40. Plumlee MH; McNeill K; Reinhard M, Indirect photolysis of perfluorochemicals: hydroxyl radicalinitiated oxidation of N-ethyl perfluorooctane sulfonamido acetate (N-EtFOSAA) and other perfluoroalkanesulfonamides. Environmental science \& technology 2009, 43 (10), 3662-3668. [PubMed: 19544870]

41. Schwarzenbach RP; Gschwend PM; Imboden DM, Environmental organic chemistry. John Wiley \& Sons: 2005.

42. Goss K-U, The $\mathrm{p} \mathrm{K}$ a values of PFOA and other highly fluorinated carboxylic acids. Environmental science \& technology 2007, 42 (2), 456-458.

43. Burns DC; Ellis DA; Li H; McMurdo CJ; Webster E, Experimental p K a determination for perfluorooctanoic acid (PFOA) and the potential impact of $\mathrm{p} \mathrm{K}$ a concentration dependence on laboratory-measured partitioning phenomena and environmental modeling. Environmental science \& technology 2008, 42 (24), 9283-9288. [PubMed: 19174905]

44. Jiang P-Y; Katsumura Y; Nagaishi R; Domae M; Ishikawa K; Ishigure K; Yoshida Y, Pulse radiolysis study of concentrated sulfuric acid solutions. Formation mechanism, yield and reactivity of sulfate radicals. Journal of the Chemical Society, Faraday Transactions 1992, 88 (12), 16531658.

45. Bao Z-C; Barker JR, Temperature and ionic strength effects on some reactions involving sulfate radical [SO4-(aq)]. The Journal of Physical Chemistry 1996, 100 (23), 9780-9787.

46. Lutze HV; Kerlin N; Schmidt TC, Sulfate radical-based water treatment in presence of chloride: Formation of chlorate, inter-conversion of sulfate radicals into hydroxyl radicals and influence of bicarbonate. Water research 2015, 72, 349-360. [PubMed: 25455043]

47. Snoeyink VL; Jenkins D, Water chemistry. Wiley: 1980.

48. World Health Organization. Chlorite and Chlorate in Drinking-water. Background document for development of WHO Guidelines for Drinking-water Quality. 2005.

49. Backe WJ; Day TC; Field JA, Zwitterionic, cationic, and anionic fluorinated chemicals in aqueous film forming foam formulations and groundwater from US military bases by nonaqueous largevolume injection HPLC-MS/MS. Environmental science \& technology 2013, 47 (10), 5226-5234. [PubMed: 23590254]

50. McKenzie ER; Siegrist RL; McCray JE; Higgins CP, Effects of chemical oxidants on perfluoroalkyl acid transport in one-dimensional porous media columns. Environmental science \& technology 2015, 49 (3), 1681-1689. [PubMed: 25621878]

51. Guelfo JL; Higgins CP, Subsurface transport potential of perfluoroalkyl acids at aqueous filmforming foam (AFFF)-impacted sites. Environmental science \& technology 2013, 47 (9), 4164 4171. [PubMed: 23566120]

52. Appleman TD; Higgins CP; Quinones O; Vanderford BJ; Kolstad C; Zeigler-Holady JC; Dickenson ER, Treatment of poly-and perfluoroalkyl substances in US full-scale water treatment systems. Water research 2014, 51, 246-255. [PubMed: 24275109] 

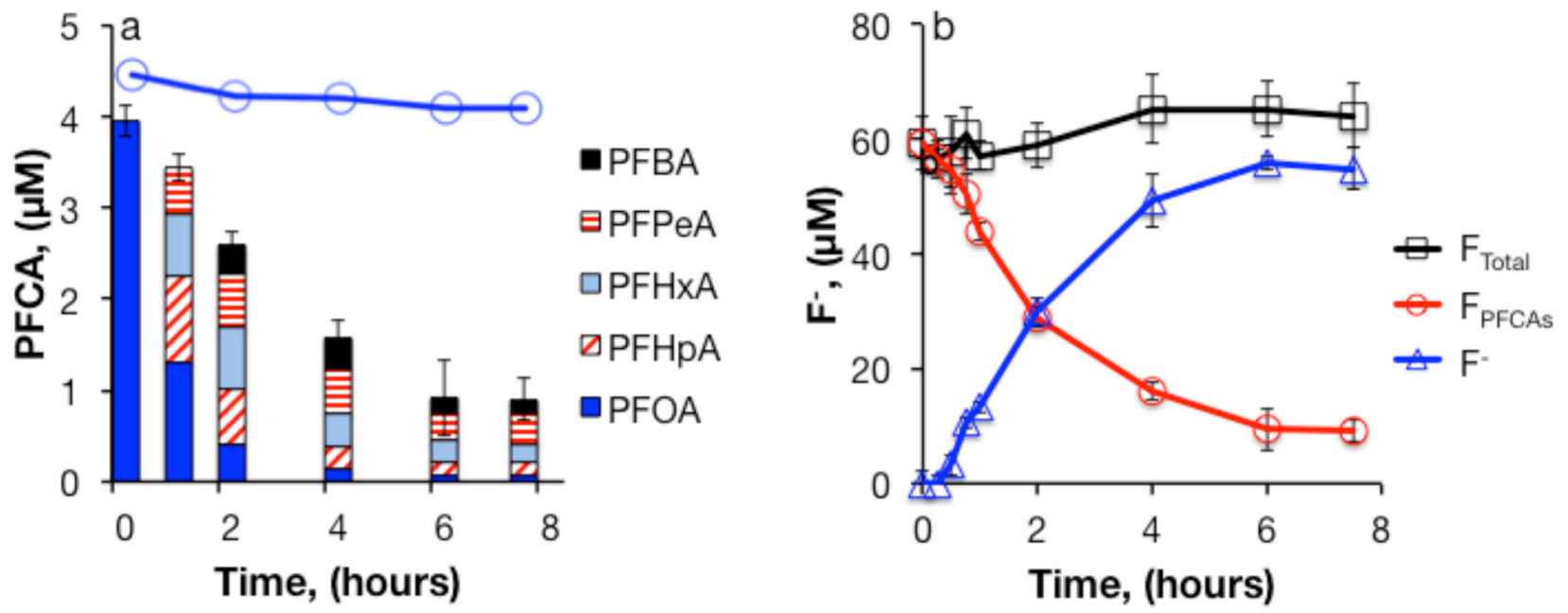

Figure 1.

Heat-activated persulfate treatment of PFOA in unbuffered water: (a) PFCAs; (b) Fluorine mass balance. $\left[\mathrm{S}_{2} \mathrm{O}_{8}{ }^{2-}\right]_{0}=50 \mathrm{mM},[\mathrm{PFOA}]_{0}=5 \mu \mathrm{M}, \mathrm{T}=85^{\circ} \mathrm{C}$. The line with open circles in panel (a) represents PFOA in persulfate-free controls $(n=1)$. 


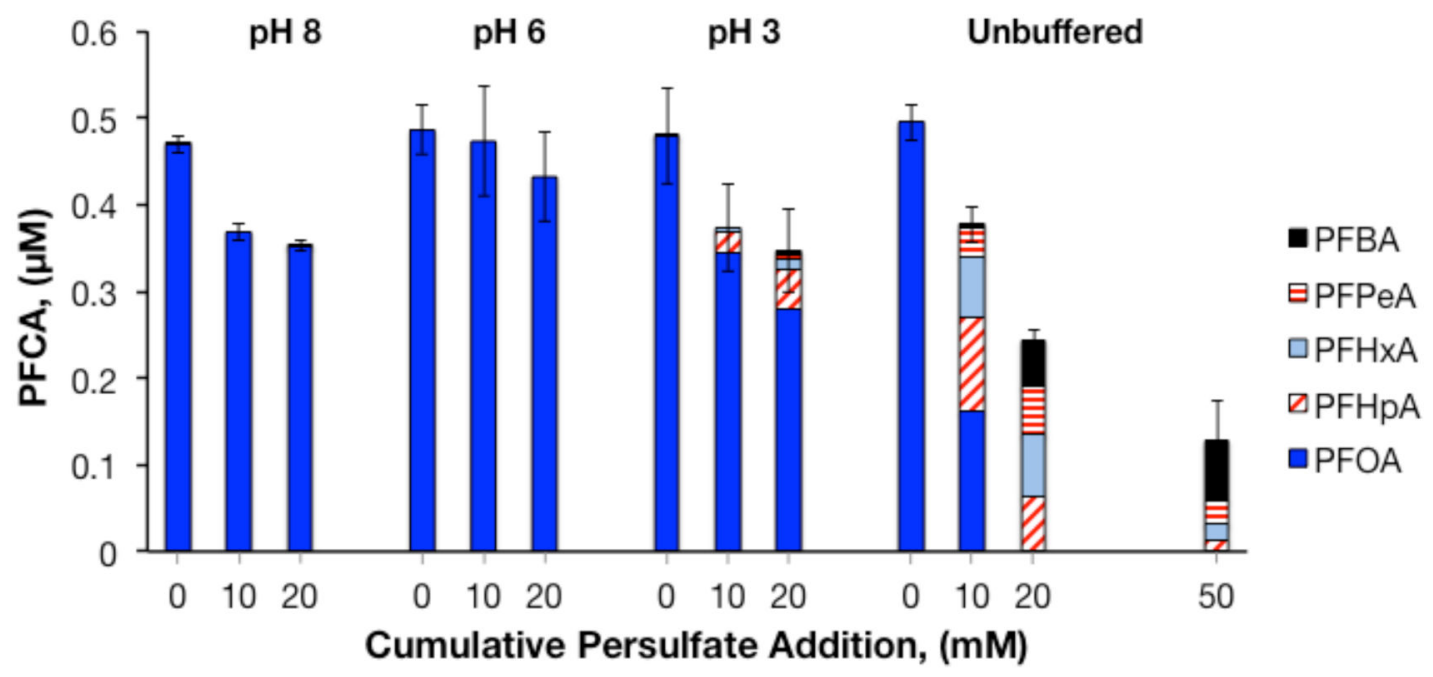

Figure 2.

Effect of $\mathrm{pH}$ on heat-activated persulfate treatment of PFOA in ultrapure water. $[\mathrm{PFOA}]_{0}=$ $0.5 \mu \mathrm{M}, \mathrm{T}=85^{\circ} \mathrm{C}$, reactors were sampled after decomposition of $\mathrm{S}_{2} \mathrm{O}_{8}{ }^{2-}$. 


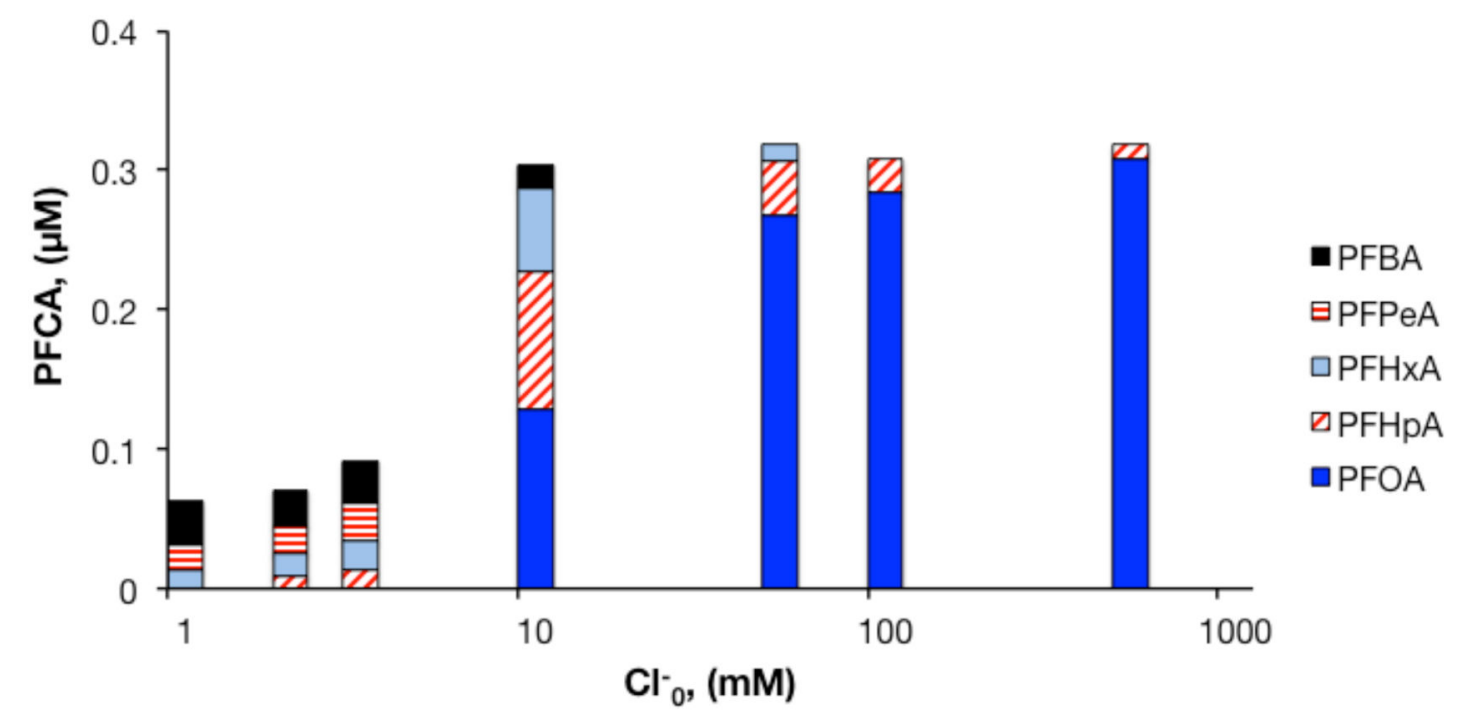

Figure 3.

Effect of initial $\mathrm{Cl}^{-}$concentration on PFCA concentrations after $7.5 \mathrm{~h}$ of heat-activated persulfate treatment of PFOA in water. $\left[\mathrm{S}_{2} \mathrm{O}_{8}{ }^{2-}\right]_{0}=50 \mathrm{mM}$, [PFOA $]_{0}=0.5 \mu \mathrm{M}$, unbuffered, $\mathrm{T}=85^{\circ} \mathrm{C}$. 

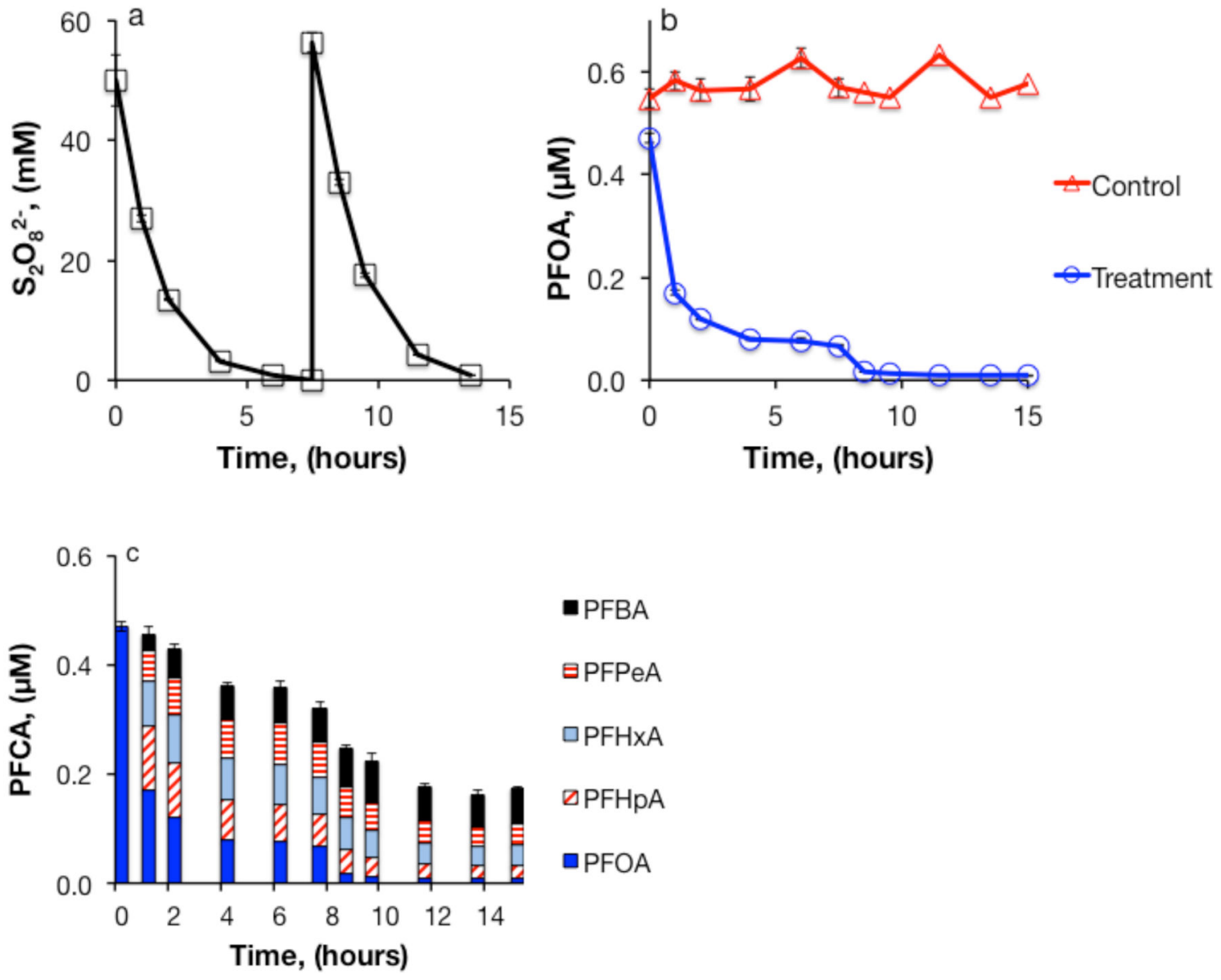

Figure 4.

Heat-activated persulfate treatment of PFOA in aquifer sediment slurry. (a) persulfate, (b) PFOA loss compared to persulfate-free control, and (c) PFCAs. $200 \mathrm{~g} / \mathrm{L}$ aquifer sediments, $\left[\mathrm{S}_{2} \mathrm{O}_{8}{ }^{2-}\right]_{0}=50 \mathrm{mM} \times 2,[\mathrm{PFOA}]_{0}=0.5 \mu \mathrm{M}$, unbuffered, $\mathrm{T}=85^{\circ} \mathrm{C}$. 